\title{
Desnutrição energético-proteica grave durante a hospitalização: aspectos fisiopatológicos e terapêuticos
}

\author{
Protein-energy malnutrition during hospital stay: physiopathology and treatment
}

\author{
Adriana Martins de Lima', Silvia Maria M. Gamallo², Fernanda Luisa C. Oliveira ${ }^{3}$
}

\section{RESUMO}

Objetivos: Apresentar a conduta para o tratamento da desnutrição energético-proteica grave e os principais aspectos fisiopatológicos da doença.

Fontes de dados: Tomando como base o Manual da Organização Mundial da Saúde (OMS, 1999), realizou-se uma busca por trabalhos publicados em inglês, espanhol e português sobre o tratamento hospitalar de crianças com desnutrição grave, nas bases de dados Lilacs, Medline e SciELO, publicados nos últimos dez anos, utilizando-se as palavras-chave: desnutrição, criança, hospitalização, terapia nutricional, diretrizes, OMS.

Síntese dos dados: Foram abordadas as principais características fisiopatológicas da desnutrição grave e a conduta recomendada para o tratamento. Identificaram-se as principais complicações clínico-metabólicas, como a hipotermia, a hipoglicemia, a desidratação e as infecções recorrentes, além da má absorção e a fase de estabilização ou de recuperação do desnutrido grave. A compreensão de todos esses conceitos relacionados à fisiopatologia da desnutrição energéticoproteica, associada ao adequado planejamento e execução da terapia nutricional, pode reduzir o risco de morbimortalidade em crianças com idade inferior a cinco anos.

Conclusões: As diretrizes da OMS devem ser implantadas levando-se em consideração a realidade de cada região e a capacitação do profissional da saúde quanto ao conhecimento da complexidade e fisiopatologia da desnutrição energéticoproteica grave, para adequado diagnóstico e tratamento. $\mathrm{O}$ sucesso do tratamento está associado ao cuidado e à atenção ao paciente.

Instituição: Escola Paulista de Medicina da Universidade Federal de São Paulo (Unifesp), São Paulo, SP, Brasil

${ }^{1}$ Mestre em Ciências pela Unifesp; São Paulo, SP, Brasil

${ }^{2}$ Pós-Graduanda em Pediatria pela Unifesp; São Paulo, SP, Brasil

${ }^{3}$ Doutora em Medicina pela Unifesp; Coordenadora do Setor de Suporte

Nutricional da Disciplina de Nutrologia Pediátrica do Departamento de Pediatria Unifesp, São Paulo, SP, Brasil
Palavras-chave: desnutrição; criança; hospitalização; terapia nutricional; Organização Mundial da Saúde.

\section{ABSTRACT}

Objective: To identify the main physiopathological aspects of severe protein-energy malnutrition and its treatment.

Data sources: Based on the World Health Organization guidelines (WHO, 1999), an electronic search for papers on hospital treatment of children with severe malnutrition was performed on Lilacs, Medline and SciELO databases. Studies in English, Spanish and Portuguese published in the last ten years were searched by the following key-words: malnutrition, child, hospitalization, nutrition therapy, practice guidelines, WHO.

Data synthesis: The main pathological aspects of severe malnutrition and its specific treatment were reviewed. The main clinical and metabolic complications of severe malnutrition were identified such as hypothermia, hypoglycemia, dehydration, usual infections, intestinal malabsorption, as well as stabilization and recovery phases, were defined. Understanding the main concepts of the physiopathology of this condition, associated with appropriate nutrition support planning, can decrease morbidity and mortality risks of children younger than five years old.

Conclusions: The implementation of the 1999 WHO guidelines should take into consideration local economic and cultural aspects, as well as the professional health care training. Due to the complexity of severe malnutrition, adequate knowledge about basic aspects of this condition helps providing adequate diagnosis and treatment.

\footnotetext{
Endereço para correspondência:

Fernanda Luisa C. Oliveira

Rua Loefgreen, 1647 - Vila Clementino

CEP 04040-032 - São Paulo/SP

E-mail: fernandalco.dped@epm.br

Conflito de interesse: nada a declarar

Recebido em: 19/2/2009

Aprovado em: 26/9/2009
} 
Key-words: malnutrition; child; hospitalization; nutrition therapy; World Health Organization.

\section{Introdução}

A desnutrição energético-proteica (DEP) pode ser definida como uma doença multifatorial de alta letalidade, capaz de promover diversas alterações fisiológicas na tentativa de adaptar o organismo à escassez de nutrientes ${ }^{(1)}$.

A complexidade do diagnóstico e tratamento da DEP, aliada à falta de preparo dos profissionais de saúde, fez com que a Organização Mundial da Saúde (OMS-1999) elaborasse um manual abordando os aspectos fisiopatológicos e o tratamento da DEP grave durante as fases de hospitalização, reabilitação e acompanhamento em unidade de saúde ${ }^{(2)}$.

Após a elaboração dessas diretrizes, alguns trabalhos foram publicados apontando não só os benefícios da adoção de tais medidas, mas também as dificuldades encontradas. No Brasil, são poucos os estudos que avaliam a implementação dessas práticas. Sarni et al analisaram a evolução de crianças internadas com desnutrição grave e tratadas de acordo com tais diretrizes. A implementação das práticas possibilitou boa reabilitação nutricional, com baixos índices de mortalidade. Os autores alertam que o atraso no diagnóstico pode ser responsável pelo maior tempo de internação e elevados índices de mortalidade, pois, no grupo estudado, havia alta porcentagem de crianças desnutridas com alguma doença associada, a chamada desnutrição secundáriai ${ }^{(3)}$.

Há relevância da implantação do protocolo da OMS em hospital terciário. As modificações no cuidado clínico contribuem para a redução da letalidade, porém foi detectada falha na monitoração das crianças, sendo os cuidados clínicos mais importantes do que a utilização de equipamentos e medicamentos de alto custo ${ }^{(4)}$. Avaliando-se a incidência de óbito nas instituições que adotaram o protocolo da OMS para o tratamento da desnutrição grave, verificou-se que, antes da implementação dessas diretrizes, a incidência de óbito era de $46 \%$, passando a $21 \%$, o que indica melhora da qualidade do atendimento ${ }^{(5)}$.

O tratamento adequado da DEP envolve o diagnóstico preciso e rápido, o uso adequado de medicamentos e a terapia nutricional. O planejamento das medidas clínicas está dividido em três etapas:

- Fase 1 ou período de estabilização: o paciente desnutrido grave deve ser considerado imunodeficiente. Devido às suas características fisiopatológicas, não tolera a administração de grandes volumes, além de necessitar de reposição de micronutrientes. A terapia nutricional deve ser adequada às necessidades energéticas de macro e micronutrientes, considerando-se o grau de estresse do paciente. Nesse momento, deve-se prevenir e tratar as complicações clínico-metabólicas que podem aumentar o risco de morte, corrigir as deficiências nutricionais específicas e iniciar a alimentação. O objetivo não deve ser a recuperação nutricional do paciente, mas sua estabilização clínico-metabólica.

- Fase 2 ou etapa de reabilitação: nessa etapa, o paciente encontra-se em estabilidade clínica e pode ser iniciada a reabilitação nutricional visando à recuperação pônderoestatural. Deve-se não só oferecer alimentação adequada, mas realizar a estimulação motora e emocional. No momento da alta hospitalar, é preciso orientar os responsáveis quanto aos cuidados realizados em domicílio, elaborar o resumo de alta (diagnóstico e tratamento) e garantir o retorno ambulatorial em uma semana.

- Fase 3 ou acompanhamento ambulatorial: acompanhamento em unidade de saúde para prevenir recaídas e assegurar a continuidade do tratamento ${ }^{(2)}$.

O objetivo deste trabalho foi apresentar de forma objetiva a conduta adotada para o tratamento da DEP grave, além de descrever os principais aspectos fisiopatológicos que norteiam a terapia nutricional durante o período de hospitalização com base no protocolo recomendado pela Organização Mundial da Saúde (1999). Foi realizada extensa pesquisa bibliográfica em revistas científicas, livros técnicos e publicações de órgãos oficiais. Utilizaram-se artigos das bases de dados Lilacs, Medline e SciELO, publicados nos últimos dez anos em português, inglês e espanhol, a respeito dos temas desnutrição, criança, hospitalização, terapia nutricional, diretrizes e OMS.

\section{Triagem da criança com DEP}

Toda criança internada deve ter seu estado nutricional avaliado. Se a criança for gravemente desnutrida, recomenda-se a identificação de sinais e sintomas compatíveis com hipoglicemia, hipotermia, desidratação/edema e infecção. Após a detecção desses distúrbios, deve-se iniciar o tratamento específico o mais rápido possível. Buscar, junto à mãe ou responsável, o maior número de informações que possam compor a história clínica da criança (Quadro 1).

Os exames bioquímicos e a investigação do processo infeccioso devem ser solicitados segundo a avaliação clínica 
durante a hospitalização e ambulatorialmente ${ }^{(6,7)}$. De acordo com a OMS, os exames complementares solicitados para crianças com desnutrição grave podem ser reunidos em grupos básicos. Os exames úteis para o tratamento são: hemoglobina ou hemograma, glicose sanguínea, eletrólitos, parasitológico e exames de cultura. Há exames necessários em determinadas condições, como esfregaço sanguíneo por microscopia indicado para pacientes de áreas endêmicas de malária, exames radiológicos do tórax quando há suspeita de pneumonias, teste cutâneo de tuberculose, teste para vírus da imunodeficiência humana (HIV) e exame do líquido cefalorraquidiano. Outros exames, como as proteínas totais e frações, principalmente a albumina, sofrem influências de processos infecciosos, não sendo bons indicadores do estado nutricional.

As medidas de peso e estatura são imprescindíveis para o diagnóstico. Considera-se desnutrição grave quando o percentual de adequação da relação peso/estatura for inferior a $70 \%$ ou o escore $Z$ da relação peso/estatura for inferior a três desvios padrão. A avaliação antropométrica precisa ser

Quadro 1 - Identificação de fatores de risco de morbimortalidade nas avaliações clínico-nutricionais e bioquímicas do desnutrido grave hospitalizado

\section{Fatores de risco de morbimortalidade do DEP grave}

Pesquisa de sintomas e sinais clínicos

- Desidratação: sede excessiva, vômitos e diarreia atual e nas últimas semanas.

- Diurese: horário que urinou pela última vez, cor.

- Edema, palidez grave.

- Distensão abdominal, aumento ou dor hepática ao toque, icterícia.

- Sistema circulatório: sinais de colapso (extremidades frias, pulso fraco, diminuição do nível de consciência).

- Olhos encovados e lesões de córneas (indicativos de deficiência de vitamina A).

- Presença de infecção: otite, amidalite, impetigo, pneumonia.

- Frequência respiratória e tipo de respiração (pneumonia ou insuficiência cardíaca).

\section{Anamnese}

- Imunizações, uso de medicamentos, presença de alergias.

- Presença de irmãos $<5$ anos, antecedentes de desnutrição e óbito entre irmãos, condições socioeconômicas, condições de moradia.

- História da desnutrição: perda de peso nos últimos tempos e fatos concomitantes.

- Antecedentes gestacionais, peso e comprimento ao nascer, complicações neonatais.

- Desenvolvimento neuropsicomotor: etapas do desenvolvimento (sentar, andar, falar).

- Antecedentes mórbidos: doenças e internações prévias.

- História de amamentação, início da introdução de alimentos, dieta atual, higienização de utensílios e alimentos, armazenamento de alimentos e sobras, preferências alimentares e aversões.

- Temperatura corporal: monitorar à admissão e durante a internação.

- Alimentação: monitoração diária da ingestão (quantidade de alimentos e volume hídrico ingerido).

- Antropométrico: medidas de peso e estatura devem ser realizadas no momento da internação. Peso aferido diariamente e estatura, semanalmente.

- Monitorar perdas fecais e diurese.

Exames bioquímicos

- Hemograma: avaliar anemia ou processo infeccioso.

- Glicemia: avaliar hipoglicemia.

- Eletrólitos: $\mathrm{Na}, \mathrm{K}, \mathrm{Ca}, \mathrm{Mg}$ e Cl.

- Culturas (nasofaringe, hemocultura, urocultura e coprocultura, quando possível) antes do início do tratamento com antibióticos. 
realizada na admissão, após a correção da desidratação ou do edema e durante todo o período de hospitalização. Avaliar o peso diariamente e a estatura, semanalmente ${ }^{(2,8)}$.

$\mathrm{O}$ uso da circunferência de braço é apontado como uma medida simples, eficaz e de boa precisão para o diagnóstico de desnutrição grave, sendo um fator preditor do risco de mortalidade. A circunferência de braço inferior a $11,5 \mathrm{~cm}$ apresenta sensibilidade e especificidade ( 46 e $91 \%$ ) para risco de mortalidade similares às do escore $Z$ de peso para estatura <-3 DP (42 e 92\%) e a sensibilidade e especificidade da identificação clínica de caquexia $(47 \text { e } 93 \%)^{(9)}$.

\section{Aspectos fisiológicos e tratamento da DEP}

A desnutrição energético-proteica grave acarreta depleção nutricional global do paciente. A diminuição dos estoques de glicogênio e gorduras promoverá redução da reserva energética, fazendo com que a massa proteica se torne fonte de energia. Além da escassez de macronutrientes, há deficiência de micronutrientes (vitamina A e E, cobre, magnésio, zinco e selênio), contribuindo para a disfunção do sistema imune, maior quantidade de radicais livres produzidos e redução da síntese de enzimas e proteínas ${ }^{(8-11)}$.
Dentre as complicações clínico-metabólicas mais frequentes da DEP, destacam-se a hipoglicemia e hiperglicemia, a hipotermia, a desidratação e a doença diarreica ${ }^{(12)}$. As variações dos níveis glicêmicos ocorrem devido à maior produção de glicose a partir de outras vias metabólicas, redução da síntese de insulina, estímulo à produção do glucagon e aumento da epinefrina circulante. Como os estoques de glicogênio são consumidos rapidamente, o organismo passa a produzir glicose por meio de aminoácidos livres e glicerol proveniente dos ácidos graxos, aumentando a neoglicogênese. Com a intensificação dessas vias alternativas de produção de glicose e a redução crescente dos estoques de macronutrientes, torna-se difícil a manutenção adequada dos níveis séricos de glicose, levando a um quadro de hipoglicemia (glicemia menor que $54 \mathrm{mg} / \mathrm{dL})^{(2)}$. Os sintomas e sinais clínicos da hipoglicemia e o tratamento específico estão descritos no Quadro 2. Deve-se ressaltar a importância da prevenção da hipoglicemia com a utilização de soro de manutenção em velocidade de infusão de glicose entre 5 e $6 \mathrm{mg} / \mathrm{kg} /$ minuto quando o desnutrido grave permanecer por longos períodos em jejum devido à doença de base ou aguardando exames complementares ${ }^{(13)}$.

Pesquisadores compararam a implementação de protocolo para o tratamento da diarreia por vibrio cholerae com o

Quadro 2 - Diagnóstico e tratamento da hipoglicemia de pacientes com DEP grave

\begin{tabular}{|c|c|c|c|c|}
\hline Sinais clínicos & $\begin{array}{l}\text { Via de } \\
\text { administração }\end{array}$ & $\begin{array}{l}\text { Correção da } \\
\text { hipoglicemia }\end{array}$ & Monitoração & Terapia nutricional \\
\hline \multirow[t]{2}{*}{$\begin{array}{l}\text { - Temperatura } \\
\text { corporal baixa } \\
\left(<36,5^{\circ} \mathrm{C}\right) \text {; } \\
\text { - Letargia (apatia); } \\
\text { - Diminuição } \\
\text { do nível de } \\
\text { consciência, } \\
\text { sonolência; } \\
\text { - Crises convulsivas; } \\
\text { - Incoordenação } \\
\text { motora. }\end{array}$} & $\begin{array}{l}\text { - Endovenosa } \\
\text { Período crítico } \\
\text { (inconsciência ou } \\
\text { crise convulsiva) }\end{array}$ & $\begin{array}{l}\text { - Ataque: } \\
5 \mathrm{~mL} / \mathrm{kg} \text { de glicose } \\
\text { a } 10 \% \\
\text { - Manutenção: } \\
\text { Velocidade de } \\
\text { infusão da glicose } \\
\text { entre } 4-6 \mathrm{mg} / \mathrm{kg} / \mathrm{min} \text {. } \\
\text { - Período de } \\
\text { estabilidade: } \\
\text { Redução da } \\
\text { velocidade de } \\
\text { infusão. }\end{array}$ & $\begin{array}{l}\text { Teste de } \\
\text { glicemia: após } \\
30 \text { minutos de } \\
\text { administração da } \\
\text { solução. }\end{array}$ & $\begin{array}{l}\text { - Iniciar a } \\
\text { administração } \\
\text { apenas no } \\
\text { período de } \\
\text { estabilidade, que } \\
\text { constitui ausência } \\
\text { de convulsão } \\
\text { e presença de } \\
\text { consciência }\end{array}$ \\
\hline & $\begin{array}{l}\text { - Oral } \\
\text { (presença de } \\
\text { capacidade de } \\
\text { deglutição) } \\
\text { - Sonda } \\
\text { Nasogástrica } \\
\text { (dificuldade de } \\
\text { deglutição ou } \\
\text { inconsciência) }\end{array}$ & $\begin{array}{l}\text { - Glicose a } 10 \% \\
\text { - Sacarose a } 10 \% \\
\text { - Glicose a } 50 \% \text { : } \\
10 \mathrm{~mL} \text { de solução em } \\
\text { água estéril } \\
\text { (diluição } 1: 4 \text { ) }\end{array}$ & $\begin{array}{l}\text { - Teste de } \\
\text { glicemia: Após } \\
30 \text { minutos de } \\
\text { administração da } \\
\text { solução. }\end{array}$ & $\begin{array}{l}\text { - Introduzir dieta } \\
\text { de } 2 / 2 \mathrm{~h} \text { por } 24 \\
\text { horas, inclusive à } \\
\text { noite para prevenir } \\
\text { hipoglicemia } \\
\text { - Manter o esquema } \\
\text { por } 48 \text { horas ou } \\
\text { mais }\end{array}$ \\
\hline
\end{tabular}


protocolo baseado no manual da OMS e atribuíram a redução do número de episódios de hipoglicemia ao início precoce da alimentação na admissão hospitalar no primeiro protocolo ${ }^{(14)}$.

Quanto à hiperglicemia, com a redução dos estoques de glicose e utilização de outras vias para produção desse suprimento, há diminuição na síntese de insulina e aumento de glucagon, epinefrina e cortisol. A elevação do cortisol promove aumento na liberação de ácidos graxos livres decorrentes da lipólise e da menor atividade da lípase lipoproteica, gerando aumento da resistência à insulina e hiperglicemia ${ }^{(15,16)}$.

A hipotermia é um distúrbio comum em crianças com DEP e pode se associar a processos infecciosos. Vale lembrar que o desnutrido grave pode não apresentar hipertermia como resposta às infecções. O controle de temperatura deve ser realizado em intervalos curtos e com a técnica correta, uma vez que o desnutrido grave apresenta aumento do oco axilar, sendo necessário pressionar o braço da criança para verificação correta da temperatura corporal. Além do controle da temperatura, devem ser implementadas medidas para manter a criança aquecida, como evitar banhos prolongados, não realizar exame físico ou trocar fraldas, roupas e lençóis em lugares abertos ou com grande circulação de ar; agasalhá-la bem e, se necessário, usar aquecedores para manter a temperatura ${ }^{(2)}$.

A desidratação é um distúrbio de difícil diagnóstico na DEP grave em virtude da ausência de sinais específicos, o que confunde o profissional de saúde, pois o desnutrido apresenta escassez de tecido subcutâneo e aparência comprometida pela própria doença. Dessa forma, alguns sinais são importantes e podem indicar a necessidade de reposição hídrica imediata. Os principais sinais e sintomas encontrados são: sede moderada, olhos encovados, pulso fraco ou ausente, extremidades frias, hipoglicemia, saliva espessa, mucosas secas e letargia. Quanto à terapia de hidratação, deve-se priorizar a via oral, limitando a endovenosa a casos graves e choque ${ }^{(2,7)}$.

Em relação à composição de micronutrientes da solução de reidratação oral utilizada, deve-se oferecer solução com menor quantidade de sódio $(45 \mathrm{mMol} / \mathrm{L})$, com minerais e eletrólitos. Utiliza-se o soro de reidratação oral padrão disponível em nosso meio diluído em $2 \mathrm{~L}$ de água, com acréscimo de $50 \mathrm{~g}$ de sacarose $(25 \mathrm{~g} / \mathrm{L})$ e $40 \mathrm{~mL}(20 \mathrm{~mL} / \mathrm{L})$ de solução de eletrólitos e minerais conforme preconizado pela OMS (1999) ou o Soro de Reidratação Oral para Crianças com Desnutrição Grave - ReSoMal (Tabela 1). Deve-se administrar cerca de 70 a $100 \mathrm{~mL}$ por $\mathrm{kg}$ de peso, iniciando-se com $5 \mathrm{~mL} / \mathrm{kg}$ a cada 30 minutos durante as primeiras duas horas e, em seguida, progredir a 6 e $10 \mathrm{~mL} /$ $\mathrm{kg}$ /hora durante as quatro a dez horas seguintes. Monitorar a quantidade ingerida de solução de reidratação oral, as perdas fecais, a diurese e a presença de vômitos, além de sintomas e sinais de hiperidratação, objetivando detectar sinais de insuficiência cardíaca ${ }^{(2)}$.

Por não apresentarem os sinais clássicos de infecção (febre, inflamação e dispneia), as manifestações clínicas de infecção em desnutridos graves podem ser apatia, sonolência, hipotermia e/ou recusa alimentar. Assim, quando não for possível a detecção do foco infeccioso, recomenda-se introduzir antibioticoterapia desde o início do tratamento, presumindo-se que essas crianças tenham infecção subclínica, com base na prevalência elevada do binômio infecção/desnutrição. Quando o tratamento é instituído precocemente, os pacientes apresentam índice de mortalidade menor do que aqueles que não recebem a antibioticoterapia ${ }^{(17)}$.

Segundo a OMS, em crianças sem sinais aparentes de infecção, orienta-se o uso de sulfametoxazol e trimetoprima $(25 \mathrm{mg} / \mathrm{kg}$ de peso/dia) por via oral, a cada 12 horas por sete dias. Em crianças com sinais clínicos de infecção ou letárgicas, substituir a medicação acima por gentamicina $(7,5 \mathrm{mg} /$ $\mathrm{kg}$ de peso/dia), via intramuscular ou endovenosa, uma vez ao dia durante sete dias. Associa-se ampicilina $(50 \mathrm{mg} / \mathrm{kg}$ de peso/dia) via intramuscular ou endovenosa a cada seis horas, por dois dias, seguida de amoxicilina $(15 \mathrm{mg} / \mathrm{kg}$ de peso/dia) via oral a cada oito horas, durante cinco dias. Em ambos os

Tabela 1 - Composição de hidratação e reposição de micronutrientes segundo a OMS (1999)

\begin{tabular}{llc}
\hline ReSoMal & Composição & mMol/L \\
\hline & Glicose & 125 \\
& Sódio & 45 \\
& Potássio & 40 \\
& Cloro & 70 \\
& Citrato & 7 \\
& Magnésio & 3 \\
& Zinco & 0,3 \\
& Cobre & 0,045 \\
& Osmolaridade & 300 \\
\hline Solução & Eletrólitos e minerais & Quantidade \\
\hline & Cloreto de potássio & $224,0 \mathrm{~g}$ \\
& Citrato tripotássico & $81,0 \mathrm{~g}$ \\
& Cloreto de magnésio & $76,0 \mathrm{~g}$ \\
& Acetato de zinco & $8,2 \mathrm{~g}$ \\
& Sulfato de cobre & $1,4 \mathrm{~g}$ \\
& Total Água q.s.p & $2500 \mathrm{~mL}$ \\
\hline
\end{tabular}


casos, se a criança não melhorar em 48 horas, adiciona-se cloranfenicol $(25 \mathrm{mg} / \mathrm{kg}$ de peso/dia) via intramuscular ou endovenosa a cada seis horas, durante sete dias ${ }^{(2)}$.

Nos centros terciários, opta-se por realizar exames complementares para identificar o foco infeccioso e orientar posterior tratamento, que deve ser feito com antibiótico de amplo espectro. A OMS recomenda a administração de metronidazol $(7,5 \mathrm{mg} / \mathrm{kg}$ de peso/dia) a cada oito horas, por sete dias, para tratar o sobrecrescimento bacteriano. Para as parasitoses, usar mebendazol: $100 \mathrm{mg}$ por via oral a cada 12 horas por três dias. Se a criança apresentar o calendário de imunizações incompleto, providenciar sua atualização rapidamente ${ }^{(2,17,18)}$.

\section{Terapia nutricional}

A terapia nutricional deve ser planejada segundo a fase de estabilização ou de reabilitação.

Quanto à via de administração, deve-se priorizar a via oral e, caso a criança apresente alguma incapacidade ou intolerância, utilizar a via nasogástrica ${ }^{(1)}$.
As metas nutricionais e a forma de administração são claramente descritas nas recomendações da OMS (Quadro 3), entretanto, tais metas podem não ser alcançadas em qualidade e quantidade em virtude das alterações fisiopatológicas ocorridas principalmente no trato digestório. Após o período de estabilização, o comprometimento de dissacaridases, como a lactase, pode ser prolongado, o que justifica o emprego de fórmulas com conteúdo restrito de lactose (Gráfico 1).

A integridade do intestino é fundamental para a absorção de nutrientes e proteção contra a invasão de bactérias e toxinas ${ }^{(19)}$. Recomenda-se o uso de fórmula artesanal ou industrializada com teor máximo de 1,3\% de lactose e conteúdo reduzido de sódio. A fórmula artesanal recomendada não apresenta a concentração proteica, de sódio e de lactose semelhante ao leite vaca (Tabela 4), além de ser aditivada com micronutrientes (oligoelementos, vitaminas e eletrólitos). O conteúdo de energia e nutrientes deve ser adaptado às fases de estabilização e de recuperação nutricional durante a hospitalização, divergindo quanto à composição nutricional, ao modo de preparo e ao esquema de administração (Quadro 3) $)^{(2)}$.

Quadro 3 - Composição das dietas segundo a OMS, 1999

\begin{tabular}{|c|c|c|c|}
\hline \multirow{2}{*}{ Dietas por $100 \mathrm{~mL}$} & \multirow{2}{*}{ Nutrientes } & F75 & F100 \\
\hline & & Estabilização & Recuperação \\
\hline \multirow[t]{8}{*}{ Nutrientes } & Energia - kcal & 75 & 100 \\
\hline & Proteína - g & 0,9 & 2,9 \\
\hline & Lactose - g & 1,3 & 4,2 \\
\hline & Potássio - mMol & 3,6 & 5,9 \\
\hline & Sódio - mMol & 0,6 & 1,9 \\
\hline & Magnésio - mMol & 0,43 & 0,73 \\
\hline & Zinco - mg & 2,0 & 2,3 \\
\hline & Cobre $-\mathrm{mg}$ & 0,25 & 0,25 \\
\hline \multirow{3}{*}{$\begin{array}{l}\text { Distribuição dos macronutrientes } \\
\text { e osmolaridade }\end{array}$} & Proteínas & $5 \%$ & $12 \%$ \\
\hline & Gordura & $32 \%$ & $53 \%$ \\
\hline & Osmolalidade - mOsm/L & 333 & 419 \\
\hline \multirow[t]{5}{*}{ Ingredientes } & Leite $-g$ & 35 & 110 \\
\hline & Açúcar - g & 100 & 50 \\
\hline & Óleo Vegetal - g & 20 & 30 \\
\hline & Solução de eletrólitos e minerais $-\mathrm{mL}$ & 20 & 20 \\
\hline & Dias/ Frequência & $\begin{array}{c}\text { Volume }(\mathrm{mL}) / \mathrm{kg} \\
\text { de peso/refeição }\end{array}$ & $\begin{array}{c}\text { Volume }(\mathrm{mL}) / \mathrm{kg} \\
\text { de peso/dia }\end{array}$ \\
\hline \multirow[t]{3}{*}{ Administração da dieta } & 1 a 2 dias $=2$ em 2 horas & 11 & 130 \\
\hline & 3 a 5 dias $=3$ em 3 horas & 16 & 130 \\
\hline & 6 a 7 dias $=4$ em 4 horas & 2 & 130 \\
\hline
\end{tabular}




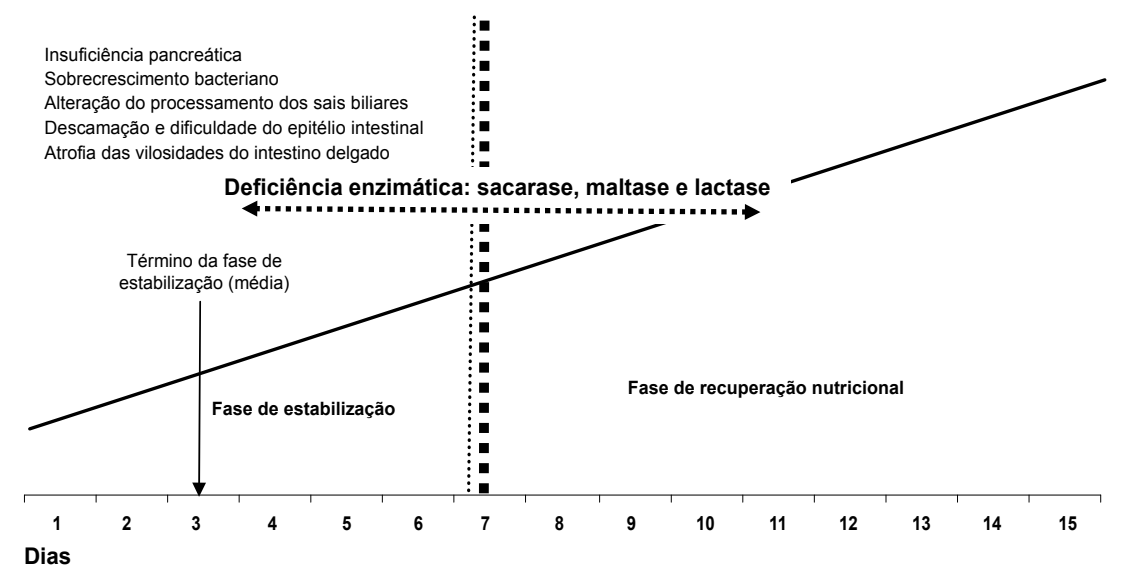

Figura 1 - Principais alterações que ocorrem no trato digestório durante as fases de estabilização e recuperação da DEP.

Na etapa de estabilização, a dieta deve fornecer no mínimo $80 \mathrm{kcal} / \mathrm{kg}$ por dia, com conteúdo proteico de $1,0-1,5 \mathrm{~g} / \mathrm{kg} /$ dia. Quantidade de energia inferior ou igual à considerada pode contribuir com a manutenção do catabolismo, enquanto valores energéticos superiores a $100 \mathrm{kcal} / \mathrm{kg} / \mathrm{dia}$ levam a alterações metabólicas, elevando o risco de morbimortalidade. Recomenda-se que, em vigência de alto grau de estresse (sepse ou meningite), a oferta de energia seja limitada ao valor da taxa metabólica basal para cada faixa etária, acrescida de $10-20 \%$.

A oferta hídrica total (dieta, soro e medicações) deve ser limitada entre 120 e $140 \mathrm{~mL} / \mathrm{kg} /$ dia. Diante da presença de edema, utiliza-se quantidade hídrica inferior, porém se houver vômitos e doenças diarreicas, repõem-se as perdas hídricas, aumentando a quantidade ofertada.

$\mathrm{Na}$ etapa de recuperação nutricional, a dieta deve se adequar à demanda aumentada da necessidade nutricional, visando atingir 1,5 a 2 vezes a recomendação energética total para a faixa etária. Para garantir a adequação dos macronutrientes, preconiza-se a utilização de módulos de carboidratos e lipídios, desde que a porcentagem máxima na somatória dos módulos utilizados não exceda $5 \% \%^{(2)}$.

Quanto à reposição de micronutrientes, em locais onde há programas de suplementação de megadoses de vitamina A, as crianças sem comprometimento ocular devem ser suplementadas nos primeiros dias de internação, com exceção daquelas que tenham recebido a dose há menos de 30 dias. Em pacientes com manifestações clínicas oculares no momento da internação, aplicar as doses recomendadas pelos programas de suplementação de megadoses de vitamina A. As outras vitaminas devem ser acrescidas à fórmula artesanal para alimentação ou sob a forma de suplementos polivitamínicos.
O tratamento da anemia ferropriva é realizado apenas na fase de recuperação nutricional. $\mathrm{O}$ momento ideal de reposição do ferro ocorre em média na segunda semana e de forma concomitante ao aumento de apetite, ganho de peso e melhora clínica do processo infeccioso ou metabólico. A suplementação oral de outros oligoelementos contidos na fórmula artesanal contribui não só para o crescimento como para o tratamento das deficiências ${ }^{(2)}$.

\section{Discussão}

Ao longo das últimas décadas, houve redução da prevalência da desnutrição grave, porém as taxas de letalidade permanecem ainda altas ${ }^{(20)}$. Man et al analisaram 13.579 crianças com idade inferior a cinco anos internadas em dois hospitais na Gâmbia. Os autores verificaram que 23\% das crianças com escore $Z$ de peso para idade inferior a -4 DP evoluíram a óbito durante o período de hospitalização, enquanto o percentual observado nas crianças com escore $Z>-2 \mathrm{dp}$ foi de $7,2 \%{ }^{(21)}$. A redução da letalidade pode ser alcançada com a implementação das diretrizes da OMS, pois o tratamento não está associado ao uso de drogas de alto custo ou mesmo a equipamentos sofisticados, mas sim à rápida identificação da desnutrição grave e à implementação de protocolo de atendimento específico a esses pacientes. $\mathrm{O}$ treinamento da equipe de saúde quanto à identificação dos sinais clínicos é estratégia importante para o tratamento da desnutrição ${ }^{(22)}$.

Inicialmente, cabe à equipe de saúde analisar de forma detalhada cada passo do documento da OMS para interpretação e, quando necessário, adaptação do protocolo em sua instituição. Posteriormente, deve-se treinar a equipe de saúde desde o pronto atendimento, com priorização da 
agilidade do processo de internação, assim como da adoção de todas as etapas do protocolo adaptadas pela instituição para identificação dos sinais e dos sintomas e execução das condutas propostas, visando à redução da morbimortalidade desses pacientes.

$\mathrm{O}$ adequado manuseio do desnutrido grave consiste em medidas profiláticas e condutas que respeitam a fisiopatologia da desnutrição energético-proteica. Agasalhar a criança, reduzir o tempo de jejum, corrigir os distúrbios hidroeletrolíticos e de micronutrientes, além de adequar a terapia nutricional segundo a etapa de tratamento, constituem os fundamentos primordiais da terapêutica do desnutrido grave internado.

A desnutrição primária grave pode ser diagnosticada erroneamente e a falta de diagnóstico de uma causa secundária acarreta falhas e demora no tratamento ${ }^{(17)}$. O desnutrido grave primário, por dificuldade socioeconômica ou falta de vínculo mãe-filho, evolui com bom ganho pôndero-estatural após resolução do processo infeccioso ou metabólico desde que sejam adotadas condutas que respeitem a fisiopatologia de sua desnutrição. A criança portadora de desnutrição secundária apresenta resposta mais lenta ao tratamento, necessitando de fórmulas infantis especiais ou dietas enterais para a recuperação nutricional. O desnutrido secundário, que não tem a causa da sua desnutrição estabelecida, necessita mais frequentemente

\section{Referências bibliográficas}

1. Sarni RO, Munekata RV. Terapia nutricional na desnutrição energético-proteíca grave. In: Lopez FA, Sigulem DM, Taddei JA, editores. Fundamentos da terapia nutricional em pediatria. São Paulo: Sarvier; 2002. p. 115-32.

2. Organização Pan-Americana de Saúde. Manejo da desnutrição grave: um manual para profissionais de saúde de nível superior (médicos, enfermeiros, nutricionistas e outros) e suas equipes auxiliares. Genebra: Organização Pan-Americana de Saúde; 1999.

3. Sarni RO, Souza FI, Catherino P, Kochi C, Ceragioli FL, Nóbrega FJ. Tratamento de crianças com desnutrição grave utilizando o protocolo da OMS: experiência de um centro de referência, São Paulo/Brasil. ALAN 2005;55:33644.

4. Falbo AR, Alves JG, Batista Filho M, Cabral-Filho JE. Implementação do protocolo da Organização Mundial da Saúde para o manuseio da desnutrição grave em hospital no nordeste do Brasil. Cad Saude Publica 2006;22:561-70.

5. Ashworth A, Chopra M, McCoy D, Sanders D, Jackson D, Karaolis N et al. WHO guidelines for management of severe malnutrition in rural South Africa hospitals: effects on case fatality and the influence of operational factors. Lancet 2004;363:1110-5.

6. Onis M, Garza C, Victora CG, Bhan MK, Norum KR. The WHO multicentre growth reference study (MGRS): rationale, planning and implementation. Food Nutr Bull 2004;25 (Suppl 1):3-84.

7. Bhan MK, Bhandari N, Bahl R. Management of the severely malnourished child perspective from developing countries. BMJ 2003;326:146-51. de fórmulas infantis especiais e até de nutrição parenteral, evoluindo com maior tempo de internação e risco de morbimortalidade ${ }^{(3)}$.

Ressalta-se a importância do acompanhamento interdisciplinar (pediatra, nutricionista, fisioterapeuta, psicóloga, terapeuta ocupacional, fonoaudióloga, assistente social) na estimulação neuropsicomotora do desnutrido grave, que deve ser iniciada durante o período de internação e reforçada na fase ambulatorial. Muitas vezes, apesar da recuperação ponderal do desnutrido grave, permanecem sequelas na área cognitiva, emocional e motora ${ }^{(23)}$.

Estudos e divulgação dos programas de implementação dessas práticas devem ser realizados para facilitar a execução do protocolo em outros centros. Alguns autores $^{(1,4,13,15,20,21,24,25)}$ apontam que as falhas na implementação desse protocolo estão relacionadas ao cuidado e à monitoração dos pacientes. Tal aspecto deve ser considerado principalmente em instituições localizadas em regiões com alta prevalência de DEP e que não dispõem de recursos humanos capacitados para a instituição do tratamento adequado.

Por fim, o tratamento da criança desnutrida grave deve se basear em conhecimento da fisiopatologia da doença e tratamento ágil durante cada etapa de hospitalização, seguindo-se o protocolo recomendado pela OMS e adaptando-o a cada realidade local.

8. Fechner A, Böhme C, Gromer S, Funk M, Schirmer R, Becker K. Antioxidant status and nitric oxide in the malnutrition syndrome kwashiorkor. Pediatr Res 2001;49:237-43.

9. Berkley J, Mwangi I, Griffiths K, Ahmed I, Mithwani S, English M et al. Assessment of severe malnutrition among hospitalized children in rural Kenya: comparison of weight for height and mid upper arm circumference. JAMA 2005;294:591-7.

10. Chandra RK. Protein-energy malnutrition and immunological responses. J Nutr 1992;122:597-600.

11. Castillo-Duran C, Heresi G, Fisberg M, Uauy R. Controlled trial of zinc supplementation during recovery from malnutrition: effects on growth and immune function. Am J Clin Nutr 1987;45:602-8.

12. Falbo AR, Alves JG. Severe malnutrition: epidemiological and clinical characteristics of children hospitalized in the Instituto Materno Infantil de Pernambuco (IMIP), Brazil. Cad Saude Publica 2002;18:1473-7.

13. Oliveira FL. Aspectos clínicos e laboratoriais da desnutrição energéticoproteíca. In: Nóbrega FJ. Distúrbios da nutrição na infância e adolescência. Rio de Janeiro: Revinter; 2007. p. 195-206.

14. Ahmed T, Ali M, Ullah MM, Choudhury IA, Haque ME, Salam MA et al. Mortality in severely malnourished children with diarrhea and use of a standardized management protocol. Lancet 1999;353:1919-22.

15. Doweiko JP, Nompleggi DJ. The role of albumin in human physiology and pathophysiology, Part III: Albumin and disease states. JPEN 1991;15:476-83. 
16. Sawaya AL. Desnutrição: conseqüências em longo prazo e efeitos da recuperação nutricional. Estud Avançados 2006;20:147-58.

17. Sarni RO, Souza FI, Catherino P, Kochi C, Oliveira FL, Nóbrega FJ. Nutritional support for malnourished hospitalized children: experience of a referral center, São Paulo, Brazil. Rev Assoc Med Bras 2005;51:106-12.

18. Berkowitz FE. Infections in children with severe protein-energy malnutrition. Pediatr Infect Dis J 1992;11:750-9.

19. Shimeles D, Lulseged S. Clinical profile and pattern of infection in Ethiopian children with severe protein-energy malnutrition. East Afr Med J 1994;71:264-7.

20. Bejon P, Mohammed S, Mwangi I, Atkinson SH, Osier F, Peshu N et al. Fraction of all hospital admissions and deaths attributable to malnutrition among children in rural Kenya. Am J Clin Nutr 2008;88:1626-31.

21. Man WD, Weber M, Palmer A, Schneider G, Wadda R, Jaffar S et al. Nutritional status of children admitted to hospital with different diseases and its relationship to outcome in the Gambia, West Africa. Trop Med Int Health 1998;3:678-86.

22. Hamer C, Kvatum K, Jeffries D, Allen S. Detection of severe protein-energy malnutrition by nurses in the Gambia. Arch Dis Child 2004;89:181-4.

23. Nóbrega FJ, Santos JM, Kawamorita E. Atuação da equipe interprofissional. In: Nóbrega FJ, editor. Distúrbios da nutrição na infância e adolescência. Rio de Janeiro: Revinter; 2007. p. 217-35.

24. Deen JL, Funk M, Guevara VC, Saloojee H, Doe JY, Palmer A et al Implementation of $\mathrm{WHO}$ guidelines on management of severe malnutrition in hospitals in Africa. Bull World Health Organ 2003;81:237-43.

25. Berti A, Bregani ER, Maneti F, Pizzi C. Outcome of severely malnourished children treated according to UNICEF 2004 guidelines: a one-year experience in a zone hospital in rural Ethiopia. Trans R Soc Trop Med Hyg 2008;102:939-44. 